\title{
Sociologia da ação pública: análise de políticas públicas com acento francês ${ }^{1}$
}

\author{
Denise do Carmo Direito ${ }^{\mathrm{I}}$
}

\section{Introdução'}

O objetivo deste texto é apresentar, por meio de revisão de literatura, uma visão geral dos conceitos e categorias que são característicos das abordagens francesas de análise da ação pública, que se consolidaram a partir dos anos 1980. O cotidiano da sociedade atual é moldado e regulado pela ação pública. As açóes mais corriqueiras, como se alimentar, dependem de políticas agrícolas, sanitárias e de transporte que possibilitam a chegada dos alimentos aos centros urbanos. Igualmente, a resolução de questóes complexas, como a redução das desigualdades sociais, está relacionada a um conjunto de políticas, como as de assistência social, de emprego, de educação, de saúde, entre outras, que contribuem para a reduçáo ou náo reproduçáo de padróes de desigualdades existentes.

Nesse sentido, a literatura francesa, ainda muito pouco explorada no Brasil, mostra-se oportuna ao responder, a partir de olhar específico e inovador, às seguintes questóes: como uma política pública é pensada e/ou implementada, quais atores são relevantes para definir o seu desenho, quais são os efeitos dessa ação pública na sociedade, entre outras. A inovação mais visível das abordagens francesas está relacionada ao que se costuma chamar de "sociologização" dos estudos da ação pública. Uma das marcas dessas abordagens é a mudança no entendimento do que é o Estado, que deixa de ser compreendido apenas a partir de conceitos de soberania ou do monopólio legítimo da força, e passa a ser analisado por meio de suas açóes concretas de intervenção nos múltiplos setores da sociedade.

Essa aproximaçáo com o campo da sociologia trouxe uma importância central para a análise dos atores em sua ação cotidiana de decidir e coordenar as açóes públicas. É importante observar que esses atores não se restringem aos que estão situados dentro do Estado, mas abrangem também os atores externos, que, por meio de uma complexa rede de relaçóes, influenciam até a forma como uma política é problematizada, o que, em alguma medida, definirá as soluçóes a serem buscadas. Por exemplo, o elevado número de jovens encarcerados pode ser compreendido como um problema de segurança pública ou como uma questão de falta de acesso a emprego, a educação e a políticas de inclusão social. A forma como o problema é enquadrado determinará que tipo de política pública será implementada. Assim, a construção da ação pública é fragmentária e coletiva, no sentido de que há interação entre atores estatais e não estatais, tanto coletivos como individuais, e de que a soma dessas diferentes visóes dará origem a um entendimento compartilhado de como deve ser o agir estatal.

A metodologia utilizada para a revisão de literatura buscou ser abrangente e sistemática. Partiu-se, inicialmente, de contatos iniciais

1 O presente trabalho foi realizado com apoio da Coordenação de Aperfeiçoamento de Pessoal de Nível Superior Brasil (Capes) - Código de Financiamento 001 e do Laboratório Printemps da Universidade de Versailles St-Quetin-en-Yvelines (UVSQ), França.

${ }^{I}$ Universidade de Brasília (UnB) - Brasília (DF), Brasil. E-mail: denisedireito.dd@gmail.com Recebido em: 07/07/2020. Aprovado em: 01/04/2021. 
com cientistas políticos franceses que indicaram dois livros que tratam especificamente da Sociologia da Ação Pública ${ }^{2}$ e outros dois que discutem a possível existência de uma abordagem francesa para a análise de políticas públicas ${ }^{3}$. A partir do exame dos livros foi possível identificar as referências bibliográficas mais citadas nessas obras, como os textos de Padioleau (1982) e Bruno Jobert e Pierre Muller (1987). Para dar amplitude à revisão bibliográfica foi feita uma pesquisa no site cairn.info, que disponibiliza os principais periódicos científicos da área, de forma a identificar artigos complementares ou mesmo críticos às categorias que são trabalhadas. $\mathrm{Na}$ busca inicial foram identificados 152 artigos. Após uma primeira triagem, foram excluídos estudos de casos específicos que utilizavam os conceitos e abordagens francesas mas tinham poucos acréscimos teóricos. Restaram 18 artigos selecionados e analisados em profundidade ${ }^{4}$, os quais, em sua maioria, foram utilizados para a elaboraçáo do presente trabalho.

O artigo é composto por esta introdução, pela conclusão e por quatro subseções. $\mathrm{O}$ segundo item traz a origem e as principais influências teóricas que formaram as abordagens francesas de análise das políticas públicas. Os dois itens seguintes, "Estado" e "Atores", apresentam os aspectos substantivos que condicionam a análise de políticas públicas a partir das abordagens presentes na sociologia da ação pública. $\mathrm{O}$ quinto item trata da Abordagem Cognitiva, que frequentemente é apresentada como complementar às noçôes de Estado e de Atores no entendimento da açáo pública, e também é usada como metodologia usual para compreender o concreto da atuação estatal. Em cada um dos itens, estáo em destaque determinados conceitos que objetivam ajudar na compreensão do exposto e facilitar eventuais buscas por questôes específicas.

\section{Origem e influências teóricas}

A área de estudo das políticas públicas na França é considerada de consolidação tardia. Três fatores concorrentes são apontados para explicar esse fato. Primeiramente, é indicada uma certa reserva de território feita pela alta burocracia francesa, que durante muitos anos manteve-se distanciada da academia e advogou prioridade para o desenvolvimento de pesquisas na área (Biland; Gally, 2018; Le Galès, 2015). A segunda questão foi o caráter tardio do acesso ao que era produzido em outros países, em especial nos Estados Unidos, em que nomes como John Dewey, já em 1927, lançava o The Public and its Problem, no qual analisa o que seria o público e a definição de problemas para o agir estatal. Semelhantemente, seu discípulo Harold Lasswell, no livro Politics: Who Gets What, When, How (Lasswell, 1958), foi pioneiro na conceituação da políticas públicas como um campo específico de estudos da ciência política, entre outros nomes e abordagens. $\mathrm{O}$ terceiro aspecto tem relaçáo com a concorrência entre esse tema e outros das ciências sociais, que apresentavam larga tradição na França e possuíam reconhecimento mundial, como a sociologia, área em que nomes como Michel Foucault e Pierre Bourdieu foram e são referências centrais,

2 Os livros analisados são: Sociologie Politique: l'action Publique (2011) de Patrick Hassenteufel e Sociologie de l'action publique (2018) de Pierre Lascoumes e Patrick Le Galès.

3 Os livros analisados são: Policy analysis in France (2018) editado por Charlotte Halpern, Patrick Hassenteufel e Philippe Zittoun e Une "French Touch" dans l'analyse des politiques publiques (2015) editado por Laurie Boussaguet, Sophie Jacquot e Pauline Ravinet.

4 A lista completa dos artigos pode ser fornecida pela autora, visto que nem todos os textos foram nominalmente citados nesta revisão. 
entre um conjunto de outros autores que marcaram o pensamento ocidental.

É consensual considerar que apenas nos anos 1970 e 1980 os estudos de políticas públicas (policy process) se consolidaram como área de conhecimento na França (Ledoux; Pollard, 2015), em um processo marcado pela tradução de autores estrangeiros, bem como pela ida de pesquisadores franceses para universidades de outros países, em especial as norte-americanas. Essa entrada tardia e as suas razóes deixaram consequências nos estudos de políticas públicas na França, os quais apresentam características próprias.

Alguns autores consideram que existe um "french touch", ou seja, uma forma específica na maneira de analisar políticas públicas na França (Dupuy; Zittoun, 2018; Hassenteufel; Smith, 2002; Halpern; Hassenteufel; Zittoun, 2018). No entanto, como apontam Boussaguet e Surel (2015) e Le Galès (2015), isso não significa que haja uma ontologia francesa, visto que o próprio processo histórico de surgimento do campo na França se deu a partir da interação com outros países e seus pesquisadores, conforme apontado acima. Entendemos como consensual e compartilhado pela grande maioria dos estudiosos franceses (Boussaguet; Jacquot; Raninet, 2015) o posicionamento de que, por questóes históricas e pelo contexto de desenvolvimento acadêmico da área, conforme será detalhado adiante, o campo da análise de políticas públicas na França apresenta características - como perspectivas, temas e metodologias - que são priorizadas pelos estudiosos franceses, sendo que vários desses aspectos são compartilhados internacionalmente ou tiveram produçōes externas como inspiração.

Inicialmente, a perspectiva francesa se diferenciou do mainstream da ciência política ao se afastar do conjunto de teorias como a da escolha racional e as utilitaristas, que consideravam os atores inseridos no processo de decisão e implementação de políticas públicas como racionais e maximizadores de seus benefícios. De forma complementar, para Jean Leca e Pierre Muller (2008), as especificidades que marcam a abordagem francesa de análise de políticas públicas estão relacionadas à tradição teórica e aos paradigmas existentes nos anos 1970 naquele país, quando identificava-se três correntes majoritárias.

A primeira abarcava as áreas da ciência da administração e do direito público. Ambas perspectivas são estado-cêntricas, sendo que a do direito público se inseria na tradição dos grandes juristas franceses, segundo os quais o bom governo seria aquele capaz de produzir regras simples, eficazes e lógicas. Já a ciência da administração se distanciava das abordagens puramente jurídicas à medida que buscava explicar a ação estatal por meio da análise das estruturas e das atividades dos órgãos que formam o Estado. Em momento posterior, a ciência da administração sofreu influência do pluralismo e passou a considerar relevante para a análise os grupos de pressão e de interesse, apontando para os autores externos ao Estado quando da análise de políticas públicas. Essas perspectivas teóricas, ligadas à administração pública e aos aspectos jurídicos, deixaram como legado a maior centralidade do Estado na literatura francesa e nas suas pesquisas, quando comparadas com estudos realizados em outros países (Leca; Muller, 2008).

A segunda grande vertente, que marca o início das análises das políticas públicas na França, está relacionada à crítica ao marxismo e sua visão mecânica do Estado, o qual estaria sempre submetido aos interesses da classe dominante e se contraporia à ideia de ação pública como ação autônoma dos atores estatais. Como herança, a perspectiva marxista deixou a noção de que há um global, ou seja, um contexto externo aos atores diretamente relacionados no processo decisório (Muller, 2015). A existência de um dentro (setor) e de um fora (global) das políticas públicas serão categorias analíticas de extrema relevância nas abordagens mais 
sociológicas da ação pública, como será detalhado ao longo deste texto.

A sociologia das organizaçóes é a terceira vertente. No entanto, ela vai além de apenas influenciar o campo, pois pode ser considerada a base das novas teorias de análise da ação pública e foi uma das responsáveis por "sociologizar" a ciência política francesa. O Centre Sociologie des Organisations (CSO $)^{5}$, que teve na direção nomes como Michel Crozier, Catherine Grémion, Erhard Friedberg e mais recentemente Christine Musselin, é peça importante nesse processo. O CSO e os pesquisadores que ali produziram suas pesquisas e textos apontaram para a necessidade de extrapolar leis e regras estabelecidas para compreender o Estado. Demonstraram que era necessário incluir nos estudos, além do mapeamento dos processos formais, a identificação dos processos informais, ou seja, as relaçôes que não estão normatizadas, mas que existem e influenciam a ação pública. Assim, a administração não é um bloco monolítico, mas se caracteriza por um conjunto de sistema de ação em que múltiplos atores, com diferentes estratégias, buscam que seu entendimento sobre determinado problema prevaleça. Só é possível desvendar os processos de implementação a partir de uma análise detalhada em que se opere a interação entre os vários atores (Leca; Muller, 2008). A sociologia das organizaçóes lega à sociologia da ação pública o entendimento da centralidade dos atores para a ação pública, a partir da racionalidade estratégica e sistêmica que atores envolvidos no processo de definição da ação pública possuem.

Essas são as principais influências teóricas que formaram o campo da análise de implementação de políticas públicas na França.
Assim, o que ficou conhecido como sociologia da ação pública é apenas uma forma de deixar claro que há perspectivas analíticas desenvolvidas e/ou aprofundadas por teóricos franceses, formadas por premissas, características e categorias específicas que se consolidaram ao longo do tempo, conforme será detalhado nos próximos parágrafos.

\section{Sociologia da açáo pública}

O desenvolvimento de novas maneiras de compreender os sentidos da ação pública deu origem ao que passou a se chamar de sociologia da ação pública ou, como define Pierre Muller, o "processo de sociologizar a análise do Estado" (Muller, 2000, p. 189). Trata-se de um conjunto de obras que utilizam categorias e referências relacionados à sociologia, tendo como foco principal a intervenção pública na sociedade. Ação pública, em substituição ao termo mais comum de política pública, é para Halpern, Hassenteufel e Zittoun (2018), precisamente, uma forma de deixar clara essa perspectiva sociológica que se agrega à análise do papel do Estado, de seus processos de governo e governança e das relaçôes estado-sociedade. Assim, a ação pública é entendida como o processo de intervenção na sociedade e seus respectivos impactos que devem ser analisados a partir dos atores que produzem essas políticas (policy makers), devendo se considerar "suas práticas, ideias e discursos, como eles se relacionam com uma grande variedade de atores do mercado e da sociedade, e os dispositivos concretos que eles usam para tornar operacionais os objetivos das políticas"6. (Halpern; Hassenteufel; Zittoun, 2018, p. 16)

5 O Centre Sociologie des Organisations (CSO) é um laboratório de pesquisas em ciências sociais, fundado em 1964, por Michel Crozier. O CSO é vinculado ao Institut d'études Politiques de Paris, conhecido como Sciences Po.

6 Do original: “...policymakers, their practices, ideas and discourses, how they engage in sustained relationships with a large variety of market and society actor, and the concrete devices they use in order to make policy objectives operational" (Halpern; Hassenteufel; Zittoun, 2018, p. 16). 
A sociologia da ação pública ocupa o espaço entre a sociologia e a ciência política (Bergeron; Hassenteufel, 2018) e avalia as relaçôes do Estado com a sociedade. No entanto, não deve ser pensada como uma única abordagem, mas como um conjunto de perspectivas que buscam compreender os sentidos da ação pública, apresentando trabalhos que colocam ênfase em seus diferentes aspectos. Dentre as abordagens, há aquelas de vertentes mais pragmáticas (Zittoun, 2014); aquelas que enfatizam análises discursivas, cujos pontos centrais são a linguagem e a argumentação que dão os sentidos da açấo pública (Durnova; Zittoun, 2013); bem como abordagens que dialogam com os preceitos da sociologia dos atores, em que advoga-se uma análise mais rigorosa relacionada às trajetórias e à socialização deles como forma de compreender como são efetivadas as políticas públicas (Genieys; Hassenteufel, 2012; Hassenteufel; Smith, 2002); além de abordagens que focam nos instrumentos da ação pública como elemento central de estudo e análise (Lascoumes; Le Galès, 2015). No entanto, todas as vertentes se referenciam de forma mais ou menos explícita às categorias, ferramentas e métodos da sociologia da ação pública, os quais detalharemos ao longo do texto.

Nesse encontro entre sociologia e ciência política, verifica-se a importância e a influência de autores não franceses na formação do campo da análise de políticas públicas (policy analysis), reforçando o entendimento de que há um toque francês, mas que o desenvolvimento do campo se dá a partir da interação com pesquisadores de outros países. Na gênese dessa troca, estão nomes como o já citado Harold Lasswell, autor central para a delimitação da política pública como campo específico de estudo da ciência política. Destacam-se também autores como Peter A. Hall, que estabeleceu esquema de análise mais atenta e sensível às dinâmicas históricas e compreende as políticas públicas como o resultado da confrontaçáo de interesses, percebendo relaçóes entre a análise das organizações e a análise de políticas públicas (Le Galès, 2015) e, semelhantemente, Paul A. Sabatier $(1993$; 1999) que formulou a noção de coalizóes de causas (advocacy coalizion), formadora de um sistema de crenças e ideais compartilhadas e influenciadora decisiva no desenvolvimento das abordagens da sociologia da ação pública (Boussaguet; Surel, 2015; Le Galès, 2015).

As especificidades das abordagens francesas apresentam aspectos substantivos no entendimento do que é o Estado e quais são as premissas e/ou condiçóes em que os indivíduos agem, mas também há aspectos de cunho metodológico que devem ser levados em conta. Nesse caso, as abordagens cognitivas se sobressaem. A seguir abordamos a conceituaçấo do Estado e a centralidade que ele possui nas abordagens franceses, que abandonam a concepçáo weberiana do Estado como um bloco homogêneo detentor legítimo do monopólio da violência, pautado pela impessoalidade das leis, e passam a compreendê-lo como um componente da sociedade inserido em interaçóes complexas.

\section{Estado}

Para compreender as diferenças entre as abordagens norte-americanas e francesas sobre o estudo das políticas públicas, é necessário analisar a posição que o Estado ocupa nessas análises. Conforme resumem Hall, Schmidt e Thatcher (2015, p. 253):

\footnotetext{
"O papel do Estado na análise das políticas públicas francesas em comparação com os estudos americanos não é apenas muito mais aparente [...], mas a natureza desse papel também difere. Enquanto em muitas análises anglo-saxônicas o Estado é analisado em termos de funçóes distintas nos mercados (propriedade, subsídios, regulamentação), na abordagem
} 
francesa é visto como constitutivo dos mercados [...]. O ator estatal é, portanto, um ator entre outros [...]"7 (Hall; Schmidt; Thatcher, 2015, p. 253).

A perspectiva sociológica entende o Estado como parte da sociedade. Assim, Estado e seu poder de regulaçáo são dois aspectos analíticos centrais, em uma realidade marcada por trocas entre indivíduos e coletivos para compor a ação pública. Segundo Lascoumes e Le Galès (2018), a ciência política tende a compreender as políticas públicas a partir de uma perspectiva top down (de cima para baixo), ou seja, a partir da análise de açóes e decisóes centralizadas no Estado e no alto funcionarismo. Já a sociologia privilegia uma racionalidade bottom up (de baixo para cima), em que é dada prioridade às interaçóes entre atores múltiplos no meio no qual a política se desenvolve (Lascoumes; Le Galès, 2018).

Apresenta-se, assim, um olhar mais ampliado para as relaçóes entre Estado e sociedade. O Estado não é entendido nem como simplesmente uma arena, nem como ator único, mas como espaço de negociação e enfrentamento de atores estatais e não-estatais, os quais possuem recursos organizacionais, financeiros, jurídicos e administrativos próprios, representam interesses múltiplos e interagem por meio de processos sociais concretos (Boussaguet; Surel, 2015). Mantém-se aqui um diálogo com a mudança de perspectiva ocorrida também na literatura norte-americana, em especial com as abordagens neoinstitucionalistas (Hall; Taylor, 2003), as quais têm nas instituições elemento central para a formação de posição, o atendimento das demandas e a organização de interesses dos mais diversos atores sociais. (Evans et al., 1985). No entanto, a diferença está na supervalorização que as vertentes do neoinstitucionalismo fazem da coerência interna das instituiçôes, em detrimento da autonomia e da ação estratégica dos atores, os quais, mesmo atuando dentro das instituiçôes, podem buscar subvertê-las (Hassenteufel, 2011).

Ao sociologizar a análise, busca-se compreender o Estado na concretude das suas açôes. Os conceitos e métodos dessa abordagem procuram descortinar o funcionamento do Estado a partir da análise e da observação dos comportamentos e estratégias dos atores que compóem os sistemas de ação, em uma busca pela pluralidade das lógicas da ação, dentro de um quadro que valoriza a dimensão das ideias que pautam as açóes estratégicas dos atores envolvidos.

Procura-se analisar o Estado no concreto, como advoga Jean Padioleau (1982), ou seja, em sua ação e na forma como efetivamente ocorre sua intervenção na sociedade. Para tanto, é necessário compreender exatamente o que se está analisando, no sentido de delimitar o escopo e o espaço do objeto em estudo. Abre-se mão de análises macro e opta-se pela definição de um campo específico de ação pública, em que é possível identificar os atores que efetivamente intervêm no processo, as formas e discursos dessa intervenção e as consequências na sociedade oriundas dessa ação.

O Estado náo deve ser compreendido como uma fonte autônoma de poder, mas como um complexo amplo e variado de atores, cuja ação coletiva e interaçóes com organizaçóes da sociedade e mercado

7 Tradução nossa. Texto original: "The role of the state in French public policy analysis compared with American studies is not only much more apparent..., but the nature of that role also differs. Whereas in many Anglo-Saxon analyses the state is analyzed in terms of distinct functions in markets (ownership, subsidies, regulation), in French approach it is seen as constitutive of markets... State actor are thus players among others..." (Hall; Schmidt; Thatcher, 2015, p. 253). 
ganham centralidade. Há a compreensão da fragmentaçáo do Estado, em que pequenos grupos de ação, sejam públicos, privados ou mesmo organizaçóes civis e coletivos sociais, participam formal ou informalmente da formulaçẫo de políticas públicas, nas várias esferas de poder. Reconhece-se a complexidade e, por consequência, enfrenta-se os desafios de pensar se e como os fragmentos se integram e se articulam (Lascoumes; Le Galès, 2018).

Assim, o Estado apresenta um "regime de governabilidade múltipla" (Laborier; Lascoumes, 2005, p. 42), no sentido de que o conjunto formado por instituiçóes, procedimentos, análises, reflexôes, cálculos e táticas, bem como atores e ideias, é que determina a forma específica do exercício do poder. Essa coordenação e negociação entre vários fatores se configuram como a construção da governança, ou seja, a busca da estabilidade entre as várias demandas para que o governo possa prestar serviços e regulamentar determinados aspectos do funcionamento da sociedade (Le Galès, 2014).

A análise sobre as arranjos sociais que permitem estabelecer a governança das açôes públicas foi um dos motores para a sociologização da análise das políticas públicas. Dois processos concomitantes colaboraram para essa mudança de perspectiva. O primeiro foi a crise fiscal que atingiu a grande maioria dos países a partir da década de 1970 . Essa crise se caracterizou pelo aumento de conflitos sociais, os quais frequentemente demandam soluçóes que ultrapassam os limites dos estados-nação. Por um lado, há a redução de recursos para financiamento das políticas públicas, em face do endividamento crescente dos estados e da adoção do ideário neoliberal de controle de déficits públicos. Por outro, é amplificada a demanda por mínimos sociais, ou seja, pela criação e manutenção de programas voltados à saúde, às transferências de renda e ao combate à pobreza, bem aumenta a demanda pela consolidação de agendas que exigem soluçóes que ultrapassam as fronteiras nacionais, como as questôes climáticas e migratórias. Essas duas forças tensionam a busca por soluçôes, em um contexto crescente de interdependência entre os países.

$\mathrm{O}$ segundo processo, em certa medida consequência do primeiro, está relacionado à construção de blocos econômicos, dentre os quais um dos mais sólidos foi aquele formado pelos países europeus com a consolidação da União Europeia. A europeização das políticas e a globalizaçáo dos debates econômicos foram centrais para que os estudiosos europeus superassem as concepçóes clássicas sobre o Estado como ator central e único. (Lascoumes; Le Galès, 2018)

Nesse contexto, foi necessário estabelecer novas maneiras de negociar e construir consensos em uma dinâmica de múltiplos atores e projetos de governo - visto que o bloco é composto por governos de ideologias diferentes $-e$, igualmente, de diversos perfis sócio-econômicos e, por conseguinte, dos vários conflitos sociais existentes nos diferentes países que compóem o bloco. É evidente que esse quadro complexificou a busca pela estabilização das demandas sociais. A sociologização da análise da ação pública ofereceu um caminho para compreender como se constroem esses consensos democráticos processos de governança - a partir da heterogeneidade e da diversidade dos países que compóem o bloco.

Como fruto dos processos de globalização/ europeizaçáo, Thomas Ribémont et al. (2018) analisam que, do ponto de vista da prática acadêmica, foram adotadas escalas analíticas da açâoo pública, considerando o nível em que a governança é negociada. Assim, há uma escala internacional, para as questóes globalizadas; uma escala de políticas europeias, que são acordadas pelo bloco; e políticas locais que englobam aquelas que são restritas a determinados 
territórios (Estado, regiáo dentro do estado, municipalidades, etc.). ${ }^{8}$

A europeização da ação pública foi também o motor para a consolidação de duas categorias analíticas - setorial e global- que ajudam a operacionalizar as análises de como ocorre a interação entre as várias escalas de análise.

\section{Análise setorial/global}

Pierre Muller (2013) se apoiou na organização das sociedades tradicionais de Émile Durkheim para conceituar sua noção de setor, que deve ser compreendido como um espaço estável de integração e de reflexão entre Estado e sociedade, o qual permite a coordenação e a mobilizaçáo de fatores internos e externos. O setor é compreendido como uma área de ação pública em que se identifica um escopo claro e onde se intermediam e se coordenam interesses específicos de impacto para a sociedade. Essa categoria ajuda a compreender o que está "dentro" e o que está "fora" do campo de análise.

Há um diálogo claro entre a categoria "setor" de Bruno Jobert e Pierre Muller (1987) e a noçáo de "campos" de Neil Fligstein e Doug McAdam (2012). Os dois últimos autores advogam que a implementação de políticas públicas é feita a partir de tecido relacional, em que a participação social se dá formal e informalmente ao longo do tempo. Nessa perspectiva, considera-se que a vida social é dominada por uma rede complexa de açóes em campos estratégicos (strategic action fields), os quais são unidades fundamentais para a ação coletiva. Sáo locus em que atores - coletivos ou individuais - interagem e dividem visões nem sempre consensuais - sobre o que é esse campo, suas regras de funcionamento e quais os temas estão em disputa. O campo é o nível intermediário da sociedade em que economia, sociedade civil e Estado se organizam.

No entanto, Charlotte Halpern e Sophie Jacquot (2015) analisam que a noção de campo é por demais ampliada e que, por isso, ela abrangeria regras organizacionais e culturais, o que levaria à perda de foco na ação pública. Para essa autoras, a noção de setor dá ao Estado maior centralidade em relação à abordagem de campos, visto que ao compreendê-lo como inserido e como mais um ator na construçâo de sentidos e regras para o setor, apontam que lhe compete uma negociação e renegociaçẫo constante da dimensão política na atividade de regular as atividades, sendo em parte o responsável por legitimar determinados interesses e grupos e marginalizar outros. Assim, "a questão setorial passa a ser a dos 'públicos' e da mudança da sociedade por meio da ação pública" (Laborier, 2015, p. 4).

A noção de setor demanda que as análises e a empiria estejam centradas em uma área específica de construção e transformação realizadas por meio da política pública, compreendida como uma forma singular de ação coletiva. Dessa forma, o setor é delimitado pelo processo de aquisição de competências para lidar com um determinado problema e pela legitimidade do Estado para agir e exercer sua autoridade (Halpern; Jacquot, 2015). O setor se estabelece pela própria compreensão daquilo que os atores estatais e não estatais, com papel ativo nessa área, compreendem como o foco da sua atuação.

Assim, as políticas agrícola, de assistência social, de saúde, de educação, entre tantas

8 Para aprofundar no debate sobre cada uma dessas escalas, que apresentam tradiçóes analíticas específicas dentro da sociologia da açáo pública, ver Ribémont et al. (2018, p. 186-245). Introduction à la sociologie de l'action publique.

9 Tradução nossa. Texto original: "La question sectorielle devient alor celle des "publics» et du changement de la société par l'action publique”. (Laborier, 2015, p. 4) 
outras áreas em que há atuação do poder público, são setores os quais adquirem configuração - normas e parâmetros - a partir de processos sociais concretos. Além dos meios organizacionais, financeiros, administrativos, jurídicos de que essas áreas dispóem, elas são frutos também das relaçôes de poder e de negociaçóes sociais complexas intermediada por mecanismos, como consultas públicas, fóruns de decisão, conselhos, comitês, entre outros, que permitem a construção de um entendimento compartilhado - chamado de referencial - sobre o que são e como devem se configurar essas áreas.

Como pontuado acima, bastante influenciados pelo processo de unificação dos países europeus e pelas discussóes sobre o neo-institucionalismo (Muller; Surel, 2002), Bruno Jobert e Pierre Muller (1987) advogaram que para compreender o setor era necessário entender que há um contexto global em que este está inserido. Esse contexto global se refere a tudo que está fora do setor mas que tem a capacidade de o influenciar e/ou o impactar.

Em certa medida, a proposta de uma análise setorial/global avança em relação às correntes neo-institucionalistas e à noção de instituiçóes como permanentes, formadoras e limitantes da ação humana, a partir do momento em que a explicação da mudança nas políticas públicas é relacionada à atuação dos vários atores envolvidos e das influências a que estão expostos nos vários níveis (escalas) em que atuam.

A mudança na escala global possivelmente terá impactos na esfera nacional e, por consequência, no setor de ação pública. A pandemia de covid-19, por exemplo, deve colocar em xeque as políticas neoliberais e de ajustes fiscais que se consolidaram desde os anos 1980, as quais tiveram como consequência colateral o subfinanciamento das políticas de saúde e assistência social em vários países. A necessidade de um novo patamar de financiamento dessas políticas, evidenciada pela crise sanitária, está sendo tratada em organismos internacionais e fóruns globais especializados, ou seja, fora do setor, por atores que funcionam, muitas vezes, como think tanks e patrocinadores de soluçóes. Seguramente, esses atores externos ao setor influenciarão os discursos e a maneira de pensar essas políticas tanto por parte dos membros de governos, como por parte de empresários e organizaçóes sociais, acarretando novos horizontes de discussão e ajustes para essas políticas.

As análises que consideram a existência de um setor que se inter-relaciona com um global, que o influencia e é por ele influenciado, permitem compreender a mudança como parte do processo. Além disso, a abordagem de setor possui um componente pragmatista relevante ao defender que as pesquisas devem recair sobre situaçóes concretas, quando há múltiplos atores envolvidos em um imbricado de intervençóes e com poderes e repertórios diferentes (Padioleau, 1982). As fronteiras do setor serão dadas pelos seus públicos, no sentido de que as diferentes categorias de atores e a multiplicidade de identidades - pública, privada, organização social - dos que participam da definiçáo e da implementação da política pública é que negociam os limites da sua atuação.

Enquanto críticos às categorias de análise setorial/global, Pauline Ravinet e Bruno Palier (2015) apontam para certa fluidez na compreensão do que é o "global", visto que apresenta contornos pouco nítidos e poderia abranger uma infinidade de questóes. Há uma ambiguidade nesse conceito que dificulta sua compreensão objetiva. Ao mesmo tempo em que "global" se relaciona por oposição ao "setorial”, também remete à globalização, conceito semanticamente espacial que aponta para uma sociedade mundialmente interligada. Ambas as perspectivas dificultam estabelecer uma fronteira do que seria esse global que influenciaria o setorial. Se o setor é aquilo que 
diz respeito a uma intervenção pública específica e é de alguma forma identificável pelos atores que compóem esse campo, o global acaba abarcando muitas possibilidades.

Em uma tentativa de explicitar o que seria a categoria "global", alguns autores trabalham com a noção de contexto a fim de detalhar de forma mais tangível o que se deve considerar objetivamente quando se busca compreender um processo decisório de política pública.

Primeiramente é necessário apontar que as abordagens da sociologia da ação pública não consideram a decisão como um momento específico, em que atores empoderados, heróicos burocratas ou eleitos, definem como será a intervenção na sociedade. Para analisar como determinada política pública foi decidida ou está sendo implementada, é necessário compreender quais foram as outras possibilidades que poderiam ter sido adotadas e por que se optou por outro caminho. Assim, deve-se considerar a realidade concreta da ação governamental em que há uma superposição de decisóes e não-decisóes, as quais estabelecem um fluxo de processo decisório (Hassenteufel, 2011).

Segundo Patrick Hassenteufel (2011), para compreender o processo decisório em sua complexidade, além de analisar as relações internas ao processo, é necessário levar em conta as múltiplas variáveis contextuais que pesam nesse fluxo. $\mathrm{O}$ contexto engloba, assim, aquilo que é exógeno às interaçóes entre os atores, mas que tem impacto na atuação deles (Hassenteufel, 2011). O contexto é capaz de formar uma representação mental e essa passa a ser uma contenção, um limite, para o agir. Assim, para analisar as mudanças na interação entre os atores é necessário considerar o contexto, a fim de identificar se alteraçóes nas opçóes estratégicas dos atores foram impactadas por mudanças exógenas à relação em si.

Patrick Hassenteufel (2011) lista seis grandes conjuntos de tipos de contextos que devem ser analisados, detalhados da seguinte forma:
- contexto sociodemográfico: são os dados relacionados a estratificação social, pirâmide etária, escala de renda, etc. Esses dados podem ter forte impacto na formulação da ação pública. Por exemplo, o rápido envelhecimento da população tem levado a mudanças no sistema previdenciário.

- contexto científico e tecnológico: trata-se de identificar conhecimento produzido por acadêmicos e/ou cientistas que possam ter impactos na sociedade. Por exemplo, as novas tecnologias de comunicação trouxeram mudanças significativas na forma de se fazer campanhas políticas partidárias, com prováveis mudanças no processo eleitoral.

- contexto do Estado: mudanças nas regras formais e informais em que os atores estatais estão inseridos podem trazer impactos significativos para o processo de formulação e decisão das políticas públicas. Forma de seleção, mudança de perfil dos profissionais do Estado, modo de organização do Estado, entre outras questóes, devem ser consideradas.

- contexto econômico: situação orçamentária, taxa de juros, entre outros, podem impactar no financiamento das políticas, o que acarretará a necessidade de renegociação dos parâmetros para determinada área.

- contexto político: questóes como calendário eleitoral, composição político-partidária de apoio ao governo, presença ou ausência de manifestaçóes públicas são aspectos que afetam a agenda e as decisóes de políticas públicas.

- contexto internacional: são eventos externos com forte impacto sobre políticas públicas, como as diferentes crises do petróleo que tiveram repercussão nas políticas econômicas, mas também nas definições sobre matriz energética que os países adotaram.

Dessa forma, o contexto, de forma similar à noção de global, é tudo aquilo que é 
externo ao campo, ou seja, decisóes que não foram tomadas dentro do setor, mas que são capazes de influenciar e impactar a forma como os atores entendem a política pública. Exemplo brasileiro recente para compreender como a mudança no contexto impóe mudanças no setor foi a aprovação, em 2016, da Emenda do Teto dos Gastos (EM no 95/2016), que estabelece o Novo Regime Fiscal e limita rigorosamente os gastos federais ${ }^{10}$. Essa decisão, tomada no contexto econômico em meio a uma situação orçamentária específica, impacta de forma substantiva as políticas sociais e torna necessária uma rediscussão de vários setores que abranja a dificuldade de ampliação de serviços públicos, como saúde, educação, serviços socioassistenciais, entre outros.

\section{Atores/mediadores}

Outra categoria central para a compreensão das abordagens francesas é a de atores. Ao se afastarem das teorias utilitaristas e da escolha racional, os pesquisadores franceses ampliaram o olhar para os atores envolvidos na implementação de políticas públicas, considerando não apenas os indivíduos, mas também os atores coletivos. Além disso, não se limitam aos que estão dentro do setor/campo, mas também levam em conta os que fazem a mediação com o que está fora desse espaço (Hassenteufel, 2011).

$\mathrm{Na}$ análise da ação pública, deve-se considerar ator aquele que é capaz de uma ação estratégica com algum impacto tangível no processo de decisão/implementação de política pública (Grossman, 2014). Compreende-se o indivíduo como detentor de uma autonomia relativa e, por conseguinte, possuidor de capacidades de ação e escolhas estratégicas em uma realidade que apresenta constrangimentos, mas que não impede a sua ação.

A atuação dos atores seria determinada por dois conjuntos de fatores. O primeiro diz respeito aos recursos disponíveis que determinam a capacidade de ação. Esses recursos podem ser materiais, como orçamento, pessoal, logístico, bem como políticos - seja a própria capacidade de mobilizar grupos de interesse, seja a de acessar eleitos ou atores políticos -, entre outros. O relevante é que esses recursos têm uma dimensão relacional, visto que apenas se transformam em recursos aqueles que têm o poder de permitir, limitar ou impedir o agir (Hassenteufel, 2011).

O segundo conjunto está relacionado ao sistema de representação do próprio ator. Esse sistema orienta a ação estratégica do ator e denota, entre outros aspectos, a maneira como ele sintetiza o problema de ação pública, sua interpretação da realidade, bem como os aspectos que norteiam o seu modo de agir, incluindo os interesses que ele persegue, os valores que compartilha com outros e a noção de finalidade de suas açôes (Hassenteufel, 2011). Para Philippe Zittoun (2014), além do entendimento de que os atores têm seu comportamento condicionado pelas interaçôes que estabelecem, eles também apresentam recursos próprios, bem como ideias e interesses que orientam a sua ação estratégica na área de atuação.

Se os apontamentos acima ajudam a definir o ator individual, o ator coletivo apresenta-se de mais difícil definição. Patrick Le Galès (2003) enumera cinco critérios para determinar a presença de um ator coletivo: a) ética; b) interesses comuns; c) mecanismos de integração; d) representação interna e externa ao coletivo; e e) capacidade de inovação.

10 A Ementa Constitucional 95/2016 limitou o crescimento das despesas ao equivalente à despesa de 2016, corrigida, em cada ano, pela inflação. 
De forma similar, Patrick Hassenteufel (2011) define os atores coletivos não estatais como grupos de pressão ou grupos de interesse que atuam de forma estruturada e organizada com recursos materiais - capacidade de financiamento - e recursos políticos - capacidade de representar um grupo - com o objetivo de atuar em conjunto com atores externos à sua organização, como administração pública, sistema judiciários, entre outros.

Os movimentos sociais são considerados atores coletivos que, além de possuírem recursos materiais e políticos, possuem o que Patrick Hassenteufel (2011) chama de recursos militantes, algo similar ao repertório de ação coletiva de Charles Tilly (1986). Esses grupos expressam os seus interesses e influenciam o debate e a decisão pública a partir de modos de açáo diretos e indiretos. De forma bastante resumida, os direitos estariam relacionados a uma ação direta junto às autoridades públicas - como lobby, ação jurídica - e os indiretos estariam direcionadas a influenciar e a formar a opinião pública como manifestaçóes públicas, açóes simbólicas, tomada de posiçáo pública, entre outros.

A amplitude das proposiçóes sobre o que e quais são os atores para as teorias da ação pública pode levar à consideração de um universo infinito a ser pesquisado. Willian Gernieys e Patrick Hassenteufel (2012) esclarecem que é necessário identificar quem são os atores que intervêm no processo de elaboração da política pública, assim como a maneira e a intencionalidade de suas ações (Genieys; Hassenteufel, 2012). Assim, atores incluídos nas análises são aqueles que desempenham funçôes e/ou papéis claros no policy-making.

Os atores, sejam individuais e/ou coletivos (políticos, funcionários públicos, representantes de empresas, da sociedade civil e das categorias funcionais, etc), em interação, significam e traduzem as transformaçóes que ocorrem dentro e fora do setor. Essa relação entre o dentro e fora do setor é feita pelos mediadores, responsáveis por dar sentido às trocas entre o setor e o global. Por meio de ajustes e da negociação com os vários atores envolvidos, o referencial do setor se consolida e se modifica. O conceito de referencial será apresentado a seguir, mas o importante neste momento é compreender que os ajustes progressivos entre o que ocorre dentro e fora do setor levam à construção de novas interpretações do mundo, e que o que está fora dele é influenciado pelas matrizes cognitivas e pelas perspectivas dos atores em um processo de intensas trocas e negociaçóes/renegociaçóes que podem dar novos sentidos ao setor.

Assim, cabe aos atores mediadores o desafio de adaptar o referencial global ao setor e redefinir a nova configuração da expressão de interesses sociais, transformando a "realidade socioeconômica inconsistente em um programa de ação política coerente" (Jobert; Muller, 1987, p. 71).

\section{Referencial}

O referencial se constitui a partir do processo constante de interaçáo entre os vários atores dentro e fora do campo. Trata-se de uma construçáo discursiva que se sobrepóe como modelo dominante de interpretação daquele tema/daquela questáo como sendo o sentido real do que está ocorrendo. Assim, por meio do processo de interação em que há disputas de entendimentos, por vezes, muito diversos e com lógicas divergentes, é que se estabelece o que se entende como sendo o setor, quais as fronteiras desse setor e quais os principais aspectos que norteiam a ação pública nessa área. Assim, o referencial emerge do processo de interação e dos aspectos cognitivos envolvidos nesse processo, mas possui também uma dimensão normativa, já que será dele que se desenhará as formas e limites da regulação da sociedade. Nas palavras de Pierre Muller (2000): 


\begin{abstract}
"Percebe-se, a partir daí, o caráter ao mesmo tempo cognitivo e normativo da ação pública, uma vez que as duas dimensóes da explicação do mundo e do estabelecimento de padrōes do mundo estão irredutivelmente ligadas em um processo de dar sentido à realidade: políticas públicas servem tanto para construir interpretaçóes da realidade quanto para definir modelos normativos de ação"11 (Muller, 2000, p. 195).
\end{abstract}

Para Jobert e Muller (1987), existe um referencial para determinado setor/campo, que seria aquilo que os atores institucionais entendem como as possibilidades e os limites do campo, entendimentos os quais originariam as regras e os procedimentos, ou seja, os instrumentos de ação pública, que delimitam a intervenção pública no cotidiano da sociedade (Lascoumes; Le Galès, 2005).

O referencial é uma das representaçóes do real e delimita a forma concreta do agir público. Ressalta-se que não há um único referencial para cada setor, mas um conjunto de referenciais elaborados a partir de diferentes grupos sociais. Cabe aos mediadores, apoiados por grupos dominantes, construir um referencial hegemônico, que é temporariamente aceito ou imposto aos outros grupos. Assim, o referencial de um setor é negociado com os vários atores, os quais possuem assimetria de posiçóes e de recursos. Dessa forma, compreender o referencial é analisar a construção de sentidos, entendendo o processo decisional como a agregaçáo de atores e de suas coalizóes discursivas, construídas por meio de estratégias argumentativas (Zittoun, 2014).

Como dito, o setor/campo não é apenas impactado por aquilo que está dentro dele, mas também aquilo que está fora. Por exemplo, as políticas neoliberais amplamente adotadas nos anos 1980 não surgiram espontaneamente dentro de cada Estado-naçáo, mas apresentaram mecanismos de difusão que influenciaram as políticas econômicas de grande parte dos países. Igualmente, as mudanças nas forças políticas presentes no campo, seja por consequência de algum processo eleitoral, seja por alguma crise que retire ou coloque algum player importante nos debates, podem acarretar reorientação nas políticas públicas. Isso é bastante comum nos processos de disputa eleitoral que muitas vezes tentam impor a sua visão de mundo "como um recurso político de forma a afirmar uma identidade própria, em uma lógica de demarcação vis-à-vis os concorrentes políticos" ${ }^{12}$ (Hassenteufel; Smith, 2002, p. 68).

Carla Tomazini (2018) ressalta que para se apreender um referencial é preciso examinar a relação entre o referencial global e os referenciais setoriais.

\begin{abstract}
"Mudanças nas políticas setoriais ocorrem quando transformaçóes no referencial global se impõem aos atores envolvidos, desqualificando quadros cognitivos e normativos. Um referencial setorial se torna dominante por estar mais próximo à hierarquia de normas impostas pelo referencial global. Ao adquirir estabilidade, esse referencial dominante especifica não somente a direção política, mas também os atores que se tornam centrais" (Tomazini, 2018, p. 30).
\end{abstract}

Para desvendar qual é o referencial de um setor e como ele foi construído, é necessário compreender o que os vários atores envolvidos nesse processo pensavam e advogavam

11 Tradução nossa. Texto original: "On prend conscience, à partir de là, du caractère à la fois cognitif et normatif de l'action publique puisque les deux dimensions d'explication du monde et de mise en normes du monde sont irréductiblement liées dans un processus de mise en sens du réel : les politiques publiques servent à la fois à construire des interprétations du réel...et à définir des modèles normatifs d'action" (Muller, 2000, p. 195).

12 Tradução nossa. Texto original: "Les politiques publiques peuvent donc aussi être appréhendées comme une ressource politique permettant affirmer une identité politique propre dans une logique de démarcation vis-à-vis de concurrents politiques" (Hassenteufel; Smith, 2002, p. 68). 
como o caminho a ser adotado, visto que é da soma dos entendimentos que se constrói a ação. Com o intuito de responder a esse desafio, muitos autores usam como suporte a teoria cognitiva, que complementa os estudos não apenas por seus aspectos analíticos, mas também pelos metodológicos.

\section{Abordagem cognitiva}

A abordagem cognitiva não é uma corrente homogênea. Está ligada ao desenvolvimento de pesquisas, como de Bruno Jobert e Pierre Muller (1987), sobre a noção de referencial; a de Peter Hall (1993) sobre o paradigma; e a de Paul Sabatier (1993; 1999) sobre o sistema de crença e das advocacy coalitions, entre outros autores. $\mathrm{O}$ ponto comum dessas teorias está na centralidade do discurso como suporte pertinente para a compreensão do processo de implementação das políticas públicas, a mediação por meio de discursos de especialistas ou de mediadores como elemento de troca entre sociedade e Estado; e na ideia de que todas as mudanças da ação pública estão ligadas à transformação dos elementos cognitivos e normativos característicos de uma política (Surel, 2014).

Segundo Pierre Muller (2000), a abordagem cognitiva apresenta um "construtivismo modesto" no sentido de que as matrizes cognitivas são produzidas pela interação dos vários atores envolvidos, mas estas tendem a se tornar autônomas em relação a esse processo de construção e se sobrepóem como modelo dominante de interpretação do mundo. A proposta é superar os dilemas do determinismo e do voluntarismo ao advogar que os atores conseguem perceber o referencial existente e, de igual forma, compreender as transformaçóes que ocorrem no contexto e que a partir de um conjunto de relaçóes e interpretaçóes causais decodificam e recodificam os acontecimentos.
Patrick Hassenteufel (2011) advoga que essa decodificação/recodificação do real é feita a partir de um sistema de representação que possui três dimensóes: a) os princípios gerais que definem a orientação do conjunto de uma política pública; b) uma grade de interpretação da realidade que corresponde ao diagnóstico dessa orientação; e c) a racionalidade e os argumentos que legitimam a orientação da ação pública. A noção do sistema de representação é uma tentativa de integrar a dimensão de paradigmas de Sabatier, de referencial de Jobert e Muller e de sistema de crenças de Peter Hall, ao advogar que pode existir um sistema de representação em um setor de política pública que gera uma produção de argumentos que visam consolidar a convicção e a visão do maior número de atores possíveis.

A abordagem cognitiva é utilizada para compreender os atores como inseridos em um contexto de valores e princípios e de visôes compartilhadas com os vários outros atores sociais, de forma que a partir da complexidade dessas relaçóes é que os indivíduos chegam a diagnósticos e soluçóes de problemas. Pierre Muller e Yves Surel (2002) ressaltam que o processo de construção de uma matriz cognitiva e normativa é também um processo de poder, visto que os atores que conseguem liderar a formação de sentido/significado consolidam, mesmo que parcialmente, a sua visão como o referencial para determinado setor e têm o reconhecimento da liderança. Assim, além de um "processo de tomada de palavra (produção de sentido) é um processo de tomada de poder (estruturação de um campo de forças)" (Muller; Surel, 2002, p. 49).

Philippe Bezes (2000) pesquisou como a alta burocracia se engajou em um forte processo de reformas administrativas na França iniciado no final da década de 1980, já que várias dessas mudanças traziam eventuais prejuízos para esse conjunto de atores. $\mathrm{O}$ autor observou uma mudança no cenário externo, visto que 
com a adesão da França à União Europeia, houve uma demanda por uniformização das regras e modernizaçáo do serviço público dos países membros. A análise demonstra que a resposta dos servidores foi reconstruir o problema de maneira satisfatória que permitisse compatibilizar essa nova visão às informaçóes que ele possuía (ideal de compatibilidade), às suas crenças anteriores (ideal de coerência e integração) e aos princípios nos quais ele acredita (ideal moral). Assim, a alta burocracia fez ajustes cognitivos redefinindo o seu papel no processo de reforma e adotando um discurso heróico sobre a necessidade de mudanças como forma de minimizar dissonâncias e participar das reformas como ator relevante.

\section{Desafio metodológico: difícil processo de encontrar ligaçáo entre cogniçáo e açáo}

Existe um claro desafio metodológico de fazer a ligação entre cognição e ação, visto que as preferências e as estratégias dos atores devem ser analisadas sob a percepção que eles mesmos mantêm do seu papel. Isso implica em trabalhar de forma rigorosa com a socialização dos atores, como forma de melhor compreender a produção, a disseminação e a atualização das representaçóes sociais, e de igual forma, analisar quais valores e teorias norteiam a atuação deles. (Hassenteufel; Smith, 2002)

Patrick Hassenteufel (2011) aponta quatro desafios metodológicos para a abordagem cognitiva. O primeiro é identificar o sistema de representação em que o ator se insere, com a ressalva de que a análise de matérias como entrevistas, relatórios, material jornalístico, entre outros, podem não traduzir exatamente essa posição, visto que são produzidos para fins específicos e poderão demonstrar mais um contexto temporal do que efetivamente aquilo que é significativo para estabelecer as estratégias dos atores. $\mathrm{O}$ segundo desafio é a própria análise do discurso e a dificuldade de retirar dessa análise os sistemas de representação apenas daquilo que objetivamente é dito. Logo, é necessário efetuar a análise considerando seus aspectos sociológicos e compreender o contexto de produção e recepção desses discursos pelos atores sociais. O terceiro desafio metodológico é o de analisar o lugar de produção e de difusão das matrizes cognitivas. É necessário analisar a construção intelectual da ação pública, como se produziram os diagnósticos que deram origem às propostas e às orientaçóes, princípios e instrumentos de ação pública. E o quarto desafio é o de compreender como os atores se apropriaram dos diferentes discursos, ou seja, qual é a racionalidade subjetiva - derivada não só da trajetória individual, mas também das interações relevantes - que dá sentido a sua estratégia de atuação.

De modo ainda mais complexo é necessário problematizar a questão metodológica para os atores coletivos, visto que há maior dificuldade de perceber os recursos de que dispóem, os interesses e o sistema de representação ao qual aderem. É necessário compreender o grau de coesão desse autor coletivo. Para isso, além das entrevistas (observaçóes diretas e/ou participantes), é necessário avaliar também o processo de construção de interesses e de estratégias coletivas, bem como o modo de organização do todo e das interaçóes interindividuais que ocorrem no seio desse coletivo (Hassenteufel, 2011).

De forma resumida, os autores que trabalham com a abordagem cognitiva, partindo de diferentes premissas, advogam que os discursos e/ou narrativas produzidas pelos atores são uma chave fundamental para identificar mais claramente os elementos empíricos que sustentam a análise dos fatores cognitivos e normativos pertinentes.

A literatura sobre análise de políticas públicas por meio de práticas discursivas tem na sua base o pragmatismo de John Dewey, em que as açóes são modeladas pelas consequências 
que geram e não pelos seus motivos geradores. A dinâmica de produção de conteúdo e dos próprios atores - individuais e/ou coletivos é modulada durante as intervençóes, a ação e as interaçóes, em uma dinâmica de desenvolvimento de culturas públicas na forma de repertórios de argumentos. (Cefaï, 2002)

É por meio do discurso que as interaçóes entre indivíduos, sejam burocratas, grupos de interesse, movimentos sociais, instituiçóes, etc., se transformam em problemas perceptíveis, agendas e conjuntos de açóes ou soluçóes. Os discursos são formatados considerando valores, preferências e normas. Como ressalta o filósofo Geoffrey Vickers (1975 apud Rein; Schön, 1993, p. 47), trata-se de "uma construção mental, parcialmente, subjetiva, largamente intersubjetiva, ou seja, baseada em um julgamento subjetivo compartilhado, e constantemente desafiada e confirmada pela experiência"13.

Para lidar com a complexidade da realidade, os indivíduos não só a simplificam utilizando seus conhecimentos prévios, sua capacidade analítica, seus valores, mas também consideram aquilo que está colocado dentro das suas vivências com outros atores, de forma a criar um esquema mental para enquadrar o problema e suas soluçóes possíveis. Identificar valores, conhecimentos e interaçóes que foram necessários para alcançar uma determinada percepção seria uma tarefa extremamente difícil, visto que os indivíduos não racionalizam suas decisões nesse nível. Até que ponto determinado entendimento advém de valores já sedimentados e a partir de onde advém do processo de interaçáo com outros indivíduos?

Outras contribuiçóes relevantes para estabelecer a relação entre intenção e gesto vieram de autores norte-americanos. Nesse cenário são relevantes obras como a organizada por Frank Fischer e Jon Forester (1993), The Argumentative Turn in Policy Analysis and Planning, e os textos de Donald Schön (1983) e de Martin Rein e Donald Schön (1993). Resumidamente, essa literatura trouxe para o centro do debate a proposta argumentativa, segundo a qual o discurso sobre o problema é a maneira como ele é entendido. Esse discurso revela um conjunto de valores e interaçóes que se estabeleceram para a construçáo do problema e suas possíveis soluçôes. Seu objetivo não é revelar esse conjunto de questóes, mas entender em termos práticos como o enquadramento discursivo dos atores revela o seu entendimento sistematizado de determinada questão. Ressalta-se que é a partir desse quadro mental (frame) que se tomam decisóes, de forma que um mesmo conjunto de evidências poderá gerar posiçóes políticas e decisóes administrativas bastante divergentes em face do quadro valorativo dos sujeitos envolvidos no processo (Rein; Schön, 1993).

Donald Schön (1983) analisa que, no cotidiano das decisóes administrativas, observa-se a reflexividade-na-ação (reflection-in-action) e a reflexividade-sobre-a-ação (reflection-on-action). A primeira é o enquadramento reflexivo do discurso, em que a execução ocorre simultaneamente ao ato de refletir e questionar sobre as açóes, e trata-se de uma reflexão espontânea e implícita que surge na ação. Assim, a produção de sentido e significado se dá na ação. A segunda perspectiva (reflection-on-action), diz respeito à análise a posteriori, ou seja, é o pensamento retrospectivo sobre o que foi feito e como pode ser melhorado. $\mathrm{O}$ processo reflexivo acarreta as mudanças nas percepçóes e, consequentemente, nas decisôes. Esse processo ocorre tanto na dinâmica

13 Tradução nossa. Texto original: "It is thus a mental construct, partly subjective, largely intersubjective, that is, based on a shared subjective judgment, anda constantly challenged and confirmed by experience”. (Vickes; Geoffrey, 1975 apud Rein; Schön, 1993, p. 147). 
de interação e na existência de controvérsias com outros atores, como em decorrência de mudanças no contexto, ou seja, nas questóes que estão fora do campo de atuação/ação propriamente dito.

Para Hassenteufel e Smith (2002), a superaçáo do desafio metodológico da abordagem cognitiva, além das entrevistas e das observaçóes participantes e, consequentemente, da análise de discurso, traz um ganho analítico ao integrar metodologias usualmente relacionadas à sociologia dos atores, como pesquisas sobre trajetória social, profissional e/ou formaçáo dos atores, as quais ajudam a compreender sua socialização e sua rede de interaçôes. Assim, essas metodologias devem ser somadas à análise de textos, documentos, relatórios e atas que permitam contextualizar e objetivar o que foi dito pelos atores.

\section{Conclusão}

Por meio de uma importaçáo seletiva ${ }^{14}$ de conceitos majoritariamente oriundos das publicaçôes norte-americanas, estabeleceu-se na França uma abordagem fortemente influenciada por uma perspectiva sociológica de análise de políticas públicas, que aos poucos ganhou contornos específicos em relação ao que estava sendo feito alhures.

$\mathrm{O}$ avanço dos estudos sobre as açốes públicas, na França, tornou usual, a partir dos anos 2000, o termo sociologia da ação pública (Hassenteufel, 2011; Lascoumes; Le Galès, 2018; Ribémont et al., 2018). Consolida-se assim uma perspectiva sociológica de análise, que significa, entre outras coisas, compreender a ação pública para além da tradiçáo norte-americana ${ }^{15}$ do entendimento de políticas públicas enquanto solução para os problemas coletivos (problem solving), perspectiva que acarreta uma análise da intervençáo estatal sob um ponto de vista normativo e limitado. Adotar o termo ação pública acarreta um alargamento do conceito. A busca passa a ser a análise da construção da governança, ou seja, de como ocorre o processo de construção de consensos democráticos, os quais estabilizam as inúmeras demandas e, por conseguinte, reduzem os conflitos sociais e possibilitam a organização/implementação da ação pública.

Assim, não se trata apenas de analisar qual a melhor forma de resolver determinado problema social, mas também de analisar como e por que determinado tema passou a compor a agenda pública; verificar quais atores construíram o referencial daquele setor; analisar quais lógicas e premissas nortearam-nos; e considerar qual escala de governança existe nesse processo, bem como quais impactos essas escolhas acarretam na sociedade.

Outro ponto central é a relativização da centralidade do Estado, considerando-o menos hierarquizado e autônomo, na adoção de duas dimensões fundamentais. A primeira é relacionada à existência de relações mais horizontalizadas entre atores estatais e náo estatais. A segunda, praticamente uma consequência da primeira, é o reconhecimento de que a açáo pública se dá em um ambiente de negociação entre atores múltiplos, que possibilitam a sua coordenação e implementação. Dessa

14 Importação seletiva é o termo usado por Halpern, Hassenteufel e Zittoun (2018, p. 5) para especificar que, quando na década de 1970 se intensificou a troca de conhecimento entre autores franceses e de fora, nem todos os conceitos foram igualmente assimilados. Como demostrado ao longo do texto, determinados temas e abordagens foram priorizados

15 Várias abordagens marcam a perspectiva de políticas públicas como sendo a busca por soluçôes de problemas coletivos. Algumas dessas tradicionais abordagens são: a sequencial de Harold Lasswell, a sistêmica de David Easton, a da escolha racional de Hebert Simon e/ou o método de comparaçóes sucessivas (incrementalista) de Charles Lindblom; entre outros autores e escolas. 
forma, as fronteiras do Estado ficam cada vez mais fluidas e ele age a partir da interação, em um processo de construção coletiva da ação pública, em oposição a uma produção estatal de políticas públicas. As interaçóes passam a ser as unidades de análise e o desafio, recompor a totalidade da ação a partir desse conjunto.

Semelhantemente, as abordagens francesas buscam demonstrar a transformação da implementação da ação pública na contemporaneidade, com análises da construção real (concreta) dessas ações, explicitando, muitas vezes, as características contraditórias e fragmentárias do Estado. Conforme analisado ao longo do texto, a sociologia da açáo pública traz não apenas um conjunto teórico, mas também oferece categorias analíticas e metodologias que dão suporte às pesquisas de campo e à análise de seus resultados.

Uma das questôes que merece aprofundamento, em momento posterior, é a de como a sociologia da ação pública foi ou está sendo considerada nas análises de políticas públicas em outros países, bem como quais alterações esse conjunto teórico sofreu como consequência da aplicação de seus conceitos em outras realidades. Alguns autores já indicaram que a utilização dessa abordagem fora das fronteiras europeias ainda é restrita, seja nos Estados Unidos da América (Halpern; Hassenteufel; Zittoun, 2018) seja nos países latinos-americanos (Barrault-Stella; Maillet; Vommaro, 2019). Contudo, elas ainda são análises superficiais que não identificaram se há complementaridade ou hibridização entre essas abordagens e outras correntes analíticas e perspectivas teóricas usualmente produzidas ou utilizadas nesses países/regiōes. Essa ampliação permitiria enriquecer os debates e explicitar de forma mais adequada os pontos de convergência e divergência das várias perspectivas analíticas da ação pública.

\section{Referências}

BARRAULT-STELLA, L.; MAILLET, A.; VOMMARO, G. Étudier les transformations de l'action publique en Amérique latine. Gouvernement et Action Publique, v. 8, n. 1, p. 9-34, 2019. https://doi.org/10.3917/gap.191.0009

BERGERON, H.; HASSENTEUFEL, P. Une contribution de la sociologie de l'action publique à l'évaluation de processus: le cas des "politiques d'organisation". Idées Économiques et Sociales, v. 193, n. 3, p. 42-50, 2018. https://doi.org/10.3917/idee.193.0042

BEZES, P. Les hauts fonctionnaires croient-ils à leurs mythes? L'apport des approches cognitives à l'analyse des engagements dans les politiques de réforme de l'Etat. Quelques exemples français (1988-1997). Revue Française de Science Politique, v. 50, n. 2, p. 307-332, 2000. https://doi.org/10.3406/rfsp.2000.395469

BILAND, E.; GALLY, N. Civil servants and policy analysis in central government. In: HALPERN, C.; HASSENTEUFEL, P.; ZITTOUN, P. (ed.). Policy Analysis in France. Bristol: Policy Press, 2018. p. 101-118.

BOUSSAGUET, L. Introduction. In: BOUSSAGUET, L.; JACQUOT, S.; RAVINET, P. (ed.). Une "French touch" dans l'analyse des politiques publiques? Paris: Sciences Po, 2015. p. 21-23.

BOUSSAGUET, L.; SUREL, Y. Des politiques publiques "à la française”? In: BOUSSAGUET, L.; JACQUOT, S.; RAVINET, P. (ed.). Une "French touch" dans l'analyse des politiques publiques? Paris: Sciences Po, 2015. p. 153-184. 
BRASIL. Câmara dos Deputados e Senado Federal. Emenda Constitucional no 95, de 15 de dezembro de 2016. Altera o Ato das Disposições Constitucionais Transitórias, para instituir o Novo Regime Fiscal, e dá outras providências. Disponível em: http://www.planalto.gov.br/ccivil_03/constituicao/emendas/emc/emc95.htm. Acesso em: 7 jun. 2021.

CEFAÏ, D. Qu'est-ce qu'une arène publique? Quelques pistes pour une approche pragmatiste. In: CEFAÏ, D.; JOSEPH, I. L'héritage du pragmatisme. La Tour d'Aigues: Editions de l'Aube, 2002. p. 52-81.

DEWEY, J. The Public and Its Problems. New York: Holt, 1927.

DUPUY, C.; ZITTOUN, P. Methods of French policy studies. In: HALPERN, C.; HASSENTEUFEL, P.; ZITTOUN, P. (ed.). Policy Analysis in France. Bristol: Policy, 2018. p. 79-94.

DURNOVA, A.; ZITTOUN, P. Les approches discursives des politiques publiques: introduction. Revue Française de Science Politique, v. 63, p. 569-577, 2013. https://doi.org/10.3917/rfsp.633.0569

FISCHER, F; FORESTER, J. (ed.). The Argumentative Turn in Policy Analysis and Planning. Durham: Duke University Press, 1993.

FLIGSTEIN, N.; MCADAM, D. A Theory of Fields. Oxford: Oxford University Press, 2012.

GENIEYS, W.; HASSENTEUFEL, P. Qui gouverne les politiques publiques? Par-delà la sociologie des élites. Gouvernement et action publique, v. 2, n. 2, p. 89-115, 2012. https://doi.org/10.3917/gap.122.0089

GROSSMAN, E. Acteurs. In: BOUSSAGUET, L.; JACQUOT, S.; RAVINET, P. (org.). Dictionnaire des politiques publiques. 4. ed. Paris: Sciences Po, 2014. p. 31-38.

HALL, P. Policy paradigm, social learning and the State: the case of economic policymaking in Britain. Comparative Politics, v. 25, n. 3, p. 275-296, 1993. https://doi.org/10.2307/422246

HALL, P.; SCHMIDT, V.; THATCHER, M. Cognitive approaches: a French touch? Tree Anglo-American perspectives on French policy analysis. In: BOUSSAGUET, L.; JACQUOT, S.; RAVINET, P. (ed.). Une "French touch" dans l'analyse des politiques publiques? Paris: Sciences Po, 2015. p. 237-257.

HALL, P.; TAYLOR, R. As três versóes do neo-institucionalismo. Lua Nova, n. 58, p. 193-223, 2003. https://doi.org/ $10.1590 /$ S0102-64452003000100010

HALPERN, C.; HASSENTEUFEL, P.; ZITTOUN, P. Policy analysis in France: introduction. In: HALPERN, C.; HASSENTEUfEL, P.; ZITTOUN, P. (ed.). Policy Analysis in France. Bristol: Policy, 2018. p. 1-24.

HALPERN, C.; JACQUOT, S. Aux frontières de l'action publique: l'instrumentation comme logique de (dé)sectorisation. In: BOUSSAGUET, L.; JACQUOT, S.; RAVINET, P. (ed.). Une “French Touch” dans l'analyse des politiques publiques? Paris: Sciences Po, 2015. p. 57-82. 
HASSENTEUFEL, P.; SMITH, A. Essoufflement ou second souffle? L'analyse des politiques publiques “à la française”. Revue française de science politique, v. 52, n. 1, p. 53-73, 2002. https://doi.org/10.3917/rfsp.521.0053

HASSENTEUFEL, P. Sociologie politique: l'action publique. Paris: Armand Colin, 2011.

JOBERT, B.; MULLER, P. L'État en action: politiques publiques et corporatismes. Paris: PUF, 1987.

LABORIER, P. Doit-on en finir avec les comparatismes? Lignes d'horizon pour une analyse hologigogne de la domination. In: BOUSSAGUET, L.; JACQUOT, S.; RAVINET, P. (ed.). Une "French touch" dans l'analyse des politiques publiques? Paris: Sciences Po, 2015. p. 85-97.

LABORIER, P.; LASCOUMES, P. L'action publique comprise comme gouvernementalisation de l'État. In: MEYET, S.; RIBÉMONT, T.; NAVES, M.-C. (dir.). Travailler avec Foucault: retours sur le politique. Paris: L'Harmattan, 2005. p. 37-60.

LASCOUMES, P.; LE GALÈS, P. Gouverner par les instruments. Paris: Sciences Po, 2005.

LASCOUMES, P.; LE GALÈS, P. Sociologie de l'action publique. Paris: Armand Colin, 2018.

LASSWELL, H. Politics: Who Gets What, When, How. New York: Meridian, 1958.

LECA, J.; MULLER, P. Y a-t-il une approche française des police publiques? Retour sur les conditions de l'introduction de l'anlyse des politiques publiques en France. In: GIRAUD, O.; WARIN, P. Politiques publiques et démocratie. Paris: La Découverte, 2008. p. 35-72.

LEDOUX, C.; POLLARD, J. L'heritage intellectuel de l'analyse des politiques publiques en France. In: BOUSSAGUET, L.; JACQUOT, S.; RAVINET, P. (ed.). Une "French touch" dans l'analyse des politiques publiques? Paris: Sciences Po, 2015. p. 203-219.

LE GALÈS, P. Le retour des villes européennes: sovietés urbaines, modialisation, gouvernement et gouvernance. Paris: Sciences Po, 2003.

LE GALÈS, P. Gouvernance. In: BOUSSAGUET, L.; JACQUOT, S.; RAVINET, P. Dictionnaire des politiques publiques. 4. ed. Paris: Sciences Po, 2014. p. 301-303.

LE GALÈS, P. Les approches françaises des politiques publiques au temps de Pierre Muller. In: BOUSSAGUET, L.; JACQUOT, S.; RAVINET, P. (ed.). Une "French touch" dans l'analyse des politiques publiques? Paris: Sciences Po, 2015. p. 185-201.

MULLER, P. L'analyse cognitive des politiques publiques: vers une sociologie politique de l'action publique.

Revue Française de Science Politique, v. 50, n. 2, p. 189-207, 2000.

MULLER, P. Les politiques publiques. Paris: PUF, 2013. 
MULLER, P. Une théorie des cycles d'action publique. Pour penser le changement systémique. In: BOUSSAGUET, L.; JACQUOT, S.; RAVINET, P. (ed.). Une “French touch" dans l'analyse des politiques publiques? Paris: Sciences Po, 2015. p. 405-435.

MULLER, P.; SUREL, Y. A análise das políticas públicas. Pelotas: Educat, 2002.

PADIOLEAU, J. G. L'Etat au concret. Paris: PUF, 1982.

RAVINET, P.; PALIER, B. Global, es-tu là? Reflexions sur une catégorie fantomatique. In: BOUSSAGUET, L.; JACQUOT, S.; RAVINET, P. (ed.). Une “French touch" dans l'analyse des politiques publiques? Paris: Sciences Po, 2015. p. 21-55.

RIBÉMONT, T. et al. Introduction à la sociologie de l'action publique. Paris: De Boeck Supérieur, 2018.

REIN, M.; SCHÖN, D. Reframing Policy Discourse. In: HAJER, M. et al. (org.). The argumentative turn in policy analysis and planning. Durham: Duke University Press, 1993. p. 145-166. https://doi.org/10.2307/j.ctv1220k4f

SABATIER, P.; JENKINS-SMITH, H. (org.). Policy change and learning: an advocacy coalition approach. Boulder: Westview, 1993.

SABATIER, P. A. Theories of the policy process. Boulder: Westview, 1999.

SCHÖN, D. A. The reflective practitioner: how professionals think in action. New York: Basic Books, 1983.

SUREL, Y. Approches Cognitives. In: BOUSSAGUET, L.; JACQUOT, S.; RAVINET, P. Dictionnaire des politiques publiques. 4. ed. Paris: Sciences Po, 2014. p. 90-98.

TILLY, C. European violence and collective action since 1700. Social Research, v. 53, n. 1, p. 159-184, 1986.

TOMAZINI, C. As análises cognitivas de políticas públicas: uma agenda de pesquisa. Política Hoje, v. 27, n. 1, p. 25-41, 2018.

ZITTOUN, P. The political process of policymaking: a pragmatic approach to public policy. New York: Palgrave Macmillan, 2014.

\section{Resumo}

Sociologia da ação pública: análise de políticas públicas com acento francês

Por meio de revisão de literatura abrangente e sistemática, esse artigo busca apresentar uma visão geral dos conceitos e categorias que são característicos das abordagens francesas de análise da ação pública, que se consolidaram a partir dos anos 1980. Essa literatura francesa, conhecida como Sociologia da Ação Pública, ainda é pouco explorada no Brasil. Ao 'sociologizar' a análise das políticas pública, se reconhece que a ação pública ocorre em um ambiente de negociação entre atores múltiplos que estão dentro e fora do Estado. O texto traz as origens e as principais influências 
teóricas que formaram as abordagens francesas, bem como aspectos substantivos que condicionam essas análises, como o entendimento do que é Estado e Atores, além de conceitos iniciais sobre a Abordagem Cognitiva, que servem de complemento analítico e, para alguns autores, de metodologia para os estudos empíricos.

Palavras-chave: Sociologia da ação pública; Políticas públicas; Estado; Múltiplos atores; Abordagem cognitiva.

\section{Abstract}

Sociology of public action: public policy analysis with a French accent

Through a systematic and in-depth literature review, this article presents an overview of categories and concepts used on French approaches to public action analysis, consolidated up from the 1980s. This literature, known as Sociology of Public Action, is still little explored in Brazil. By "sociologizing" public policy analysis, we understand that public action occurs within a negotiation environment between multiple actors inside and outside the State. The text analyzes the origins and main theoretical influences that formed the French approaches, as well as substantive aspects related to these analyzes, such as the understanding of what is State and Actors, and initial concepts on Cognitive Approach, which serve as an analytical complement and, for some authors, as a methodology for empirical studies.

Keywords: Sociology of public action; Public police; State; Multiple actors; Cognitive approach.

\section{Résumé}

Sociologie de l'action publique : une analyse des politiques publiques à la française

Parle biais d'une revue bibliographique approfondie et systématique, cet article présente un panorama des concepts et catégories caractéristiques des approches françaises de l'analyse de l'action publique, consolidées depuis les années 1980. Cette littérature française, connue sous le nom de Sociologie de l'action publique, est encore peu explorée au Brésil. En «sociologisant» l'analyse des politiques publiques, elle comprend l'action publique comme un processus de négociation entre des multiples acteurs à l'intérieur et à l'extérieur de l'Etat. Le texte apporte les origines et les principales influences théoriques qui ont formé les approches françaises, ainsi que les aspects substantiels qui conditionnent ces analyses, comme la compréhension de ce qu'est l'État et les acteurs. L'article apporte aussi les concepts initiaux de l'Approche cognitive, qui servent de complément analytique et, pour certains auteurs, de méthodologie pour les études empiriques.

Mots-clés : Sociologie de l'action publique ; Politiques publiques ; Multiples acteurs ; Approche cognitive. 